\title{
Gingival Bleeding in Children: Causes and Treatments
}

\author{
Mohammed Karimi DMD* \\ Department of Pediatric Dentistry, Iran \\ *Corresponding author: Mohammed Karimi, Department of Pediatric Dentistry, Iran
}

\section{Opinion}

Some parents may be confronted with gingival bleeding of their children, but they feel indifferent to it because they feel that this is normal. They should know that there are several reasons for it, but the most important is the" periodontal disease". Gingival bleeding is one of the common symptoms of periodontal disease. Gingival bleeding is often due to the lack of proper removal of plaque from the teeth in the gum line, which leads to gingival inflammation. However, bleeding in the gums may be associated with serious illnesses, such as leukemia and disruption of coagulation and platelet disorders. In these conditions, it is usually easy to bleed or bruise anywhere in the body. In the following, some common causes, risk factors, and methods for treating gingival bleeding and time of referral to the dentist will be presented.

\section{Causes}

The emergence of these causes can be due to systemic and local factors.

\section{Injury and Trauma}

Gingival bleeding may be caused by traumatic injury of teeth or gingival laceration, teeth cleaning by toothpicks or sharp instruments and even foreign objects, inappropriate brushing, and flossing. The injury may also occur due to stimulation of acids and chemicals in food, drinking beverages, side effects of medicines and dental bleaching materials [1].

\section{Periodontal Disease}

If a child's' gums are easily bleeding or red, swollen and sensitive, then they may have periodontal disease. It can be caused by several factors but is often associated with poor oral and dental health [1]. This disease has two stages:

a) Gingival Inflammation: One of the main causes of gingival bleeding is the formation of plaque on the gum line. This causes inflammation and gums swelling. b) Periodontitis: Plaques gradually become hardened and become massive. This causes more bleeding and can lead to a more advanced type of gum and bone disease called periodontitis.

\section{Toothbrush}

New toothbrushes with hard bristles can sometimes cause bleeding of the gums. If a new toothbrush has recently been selected, its bristle, hardness, and rigidity should be controlled. Parents should always choose soft toothbrushes for their children. These kinds of toothbrushes like the hard one does the same job and clean the children teeth. Interestingly, they do not cause too much pressure on the gums and teeth like the hard one. Furthermore, children should not brush their teeth with great pressure because it might lead to bleeding and damage to the sensitive gums. If the bristles are bent or frayed, kids may be pressing too hard on their gums resulting in trauma to the gingiva.

\section{Flossing the Teeth}

If the kid has recently started to use dental floss, there may be a minor bleeding. This is since the gingival sulcus area is extremely sensitive and can easily be damaged by inappropriate way of flossing. Gingival bleeding usually disappears in less than a week. If the child continues to have gingival bleeding for more than a week after starting dental flossing, she should be taken to the dentist because it may indicate a more severe condition that requires treatment.

\section{Hematological Disorders and Coagulopathies}

Gingival bleeding can also occur due to abnormalities in blood such as hemophilia, leukemia, and disruptions of coagulation in the blood [1-5].

\section{Systemic Disorders}

Gingival bleeding may also be caused by systemic disorders such as liver, kidney and cardiovascular disorders, vascular disease, and diabetes $[1,6-8]$. 


\section{Medications and Treatments}

Gingival bleeding can also be due to the side effects of some medications such as blood thinners (Aspirin and Heparin) and pain medications. These medications decrease the blood's ability to clot, which can lead to easier bleeding. Chemotherapy and radiation therapy may also lead to bleeding gums. Overgrowth of gingiva can be caused by the use of Phenytoin, Cyclosporine, and Nefidipine $[1,11]$.

\section{Other Reasons}

The following can affect the incidence of gingival bleeding:
a) Tooth infection
b) Infection of the gums $[1,9]$
c) Scurvy $[1,12]$
d) Vitamin K deficiency

\section{Associated Risk Factors}

The main cause of periodontal disease is the plaque, but other factors affect the health of child's gums.

\section{Family History}

Many children have a genetic predisposition to gum disease. Genetic testing can be done to detect such a problem early before appearing the symptoms of gum disease. By doing this, Preventive measures can help keep the teeth in good condition.

\section{Unbalanced Diet}

Consuming a diet that does not have the necessary nutrients can undermine the immune system and disrupt the body's ability to cope with infections. Since periodontal disease often starts with an infection, a weak diet can exacerbate the disease. In addition, obese children are more likely to develop periodontal disease [1,9].

\section{Symptoms that may Appear with Bleeding Gums}

Gingival bleeding may be accompanied by other symptoms that affect the area of the gum, including:
a) Bad Breath
b) Bright red or reddish gums
c) The sensitivity of the gums to the touch
d) Tooth loss or tooth mobility
e) Pain or sore in the mouth
f) Problem using orthodontic tool
g) Gingival recessions
h) Gingival inflammation

\section{Symptoms that may Indicate a Serious Problem}

In some cases, gingival bleeding may be accompanied by other symptoms that indicate a serious illness and should be investigated promptly. Symptoms that the child may have with gum bleeding include:
a) Bleeding anywhere else in the body
b) Lethargy or altering consciousness or unconsciousness
c) High fever
d) Teeth loss without any reasons

\section{Treatments}

\section{Scaling}

If the child has a mild type of gingivitis, it can be treated with a professional scaling and applying the proper oral hygiene instructions. But if the condition has worsened, the dentist may use necessary different treatment approaches for children including scaling, application of mouthwash, antibiotic or other medications [10].

\section{Brushing Teeth Gently}

Parents must assure that children brush their teeth correctly. Some kids brush their teeth with too much pressure or false method of brushing, which leads to gum injuries and make their gums prone to infections.

\section{Regular Use of Dental Floss}

To prevent gum problems, remind children that regular use of dental floss is important. Flossing takes only a few minutes, but it does make sure the gums are kept healthy.

\section{Having a Balanced Diet}

A diet which is rich in vitamin $\mathrm{C}$ and calcium can be an effective way to reduce the risk of developing gum disease.

\section{Drinking Plenty of Water}

Let children Get used to drinking lots of water, especially after eating anything. This prevents food particles from sticking to the teeth and prevents the formation of plaque on the tooth surfaces.

\section{Consumption of Food Containing Vitamin C}

Eating high-quality fruits containing vitamin C prevents gum problems, such as gingivitis. Fruits rich in vitamin $\mathrm{C}$ include oranges, lemons, and etc. Parents can also give their children vitamin $\mathrm{C}$ supplements. Raw vegetables are also very effective in providing the nutrients needed by the body. In addition, chewing raw vegetables helps improve blood circulation in the gum and prevents gingival bleeding.

\section{Gargle Salt Water}

This method is one of the easiest home remedies available to prevent gum bleeding. Unfortunately, most children are unwilling to do this, and it is unpleasant for them. Instead, for this category of children, it is recommended to use an especial kid's mouthwash. 


\section{When Should Medical Help be Sought?}

In the following circumstances, the parents should refer to the dental office for further evaluations and examinations.

a) A child with chronic bleeding gum.

b) Gingival bleeding continues even after treatment.

c) Evidence of other unexplained signs and symptoms along with bleeding gums.

d) Teeth loss without any reasons.

e) Bleeding anywhere else in the body.

\section{References}

1. Bascones Martínez A, Criado Cámara E, Bascones Ilundáin C, Herrera SA Bascones Ilundáin J (2011) Etiology of Gingivitis. In: Gingival DiseasesTheir Aetiology, Prevention and Treatment, In Tech 4: 55-70.

2. Carranza FA (2006) Classification of diseases of the periodontium, In: Carranza FA and Newman MG. Clinical Periodontology. $\left(10^{\text {th }}(\mathrm{edn}), \mathrm{WB}\right.$ Saunders Company, Philadelphia, USA, p. 58-81.

3. MT Brennan, V Sankar, L Baccaglini, Pillemar SR, Kingman A, et al. (2001) Oral manifestations in patients with aplastic anemia Oral Surg Oral Med Oral Pathol Oral Radiol Endod 92(5): 503-508.
4. E Sepúlveda, U Brethauer, J Rojas, Le Fort P (2006) Oral manifestation of aplastic anemia in children J Am Dent Assoc 137(4): 474-478.

5. Chapple ILC, Saxby MS, Murray JA (1999) Gingival hemorrhage, myelodysplastic syndrome, and acute myeloid leukemia. A case report. J Periodontol 70(10): 1247-1253.

6. Wu J, Fantasia JE, Kaplan R (2002) Oral manifestations of acute myelomonocytic leukemia: a case report and review of the classification of leukemia. J Periodontol 73(6): 664-668.

7. Wolfe MD, Carlos JP (1987) Periodontal disease in adolescents: Epidemiologic findings in Navajo Indians. Community Dent Oral Epidemiol 15(1): 33-40.

8. How stuff works Bleeding gums diabetes mellitus Taiwo JO (1995) The severity of necrotizing ulcerative gingivitis in Nigerian children, Periodontal Clin Invest 17: 24-27.

9. Smith BW, Dennison DK, Newland JR (1987) Acquired HIV deficiency syndrome: Implications for the practicing dentist. Va Dent J 63:38-42.

10. Seymour RR, Ellis JS, Thomason JM (2000) Risk Factors for drug-induced gingival overgrowth. J Clin Periodontal 27(4): 217-223.

11. Armitage G (1999) Development of a classification system for periodontal diseases and conditions. Ann Perodontol 4(1): 1-6.

12. DeAngelo S, Murphy J, Claman L, Kalmar J, Leblebicioglu B (2007) Hereditary gingival fibromatosis - A review. Compend Contin Educ Dent 28(3): 138-143.

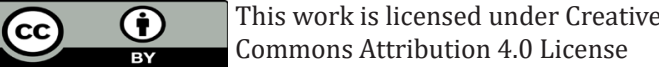

To Submit Your Article Click Here:

Submit Article

DOI: $10.32474 /$ IPDOAJ.2019.02.000138

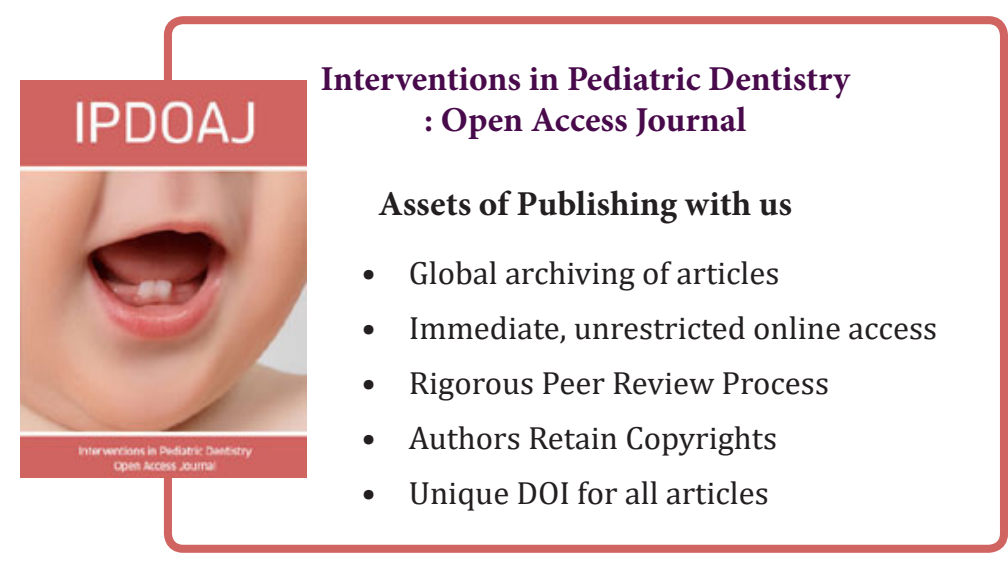

